\title{
A METÁFORA NA POESIA INGLESA DE FERNANDO PESSOA.
}

\author{
Catarina Tereza Feldmann
}

Confrontando os poemas ingleses de Fernando Pessoa com seus escritos em prosa, sobretudo os artigos de $A$ Nova Poesia Portuguesa, onde explica os princípios da poesia portuguesa moderna, tais poemas em uma língua que não a sua materna permitem equacionar seus processos criativos.

De fato, bem antes de se iniciar como poeta em vernáculo, aquele que viria a ser o maior poeta português moderno compôs largamente em língua inglesa. Havia freqüentado escolas inglesas em Durban e em inglês desabrochara para a vida intelectual. E mais, esse idioma parece ter ficado para sempre como a língua de sua inteligência: nela pensava e estruturava seus esquemas mentais. Também foram de língua inglesa os primeiros poetas e escritores que o influenciaram como Shakespeare, Milton, Coleridge, Wordsworth, Shelley, Byron, Emerson, Poe. Whitman, etc. Compreende-se, assim, porque Pessoa se lançou às primeiras tentativas poéticas em inglês: dominando a língua estrangeira com perfeição e tendo definido seus padrões estéticos ideais baseado nas leituras que fizera de poetas que se exprimiram nesse idioma, valia-se do mesmo meio de expressão para se aproximar de seus modelos. Além disso, em inglês podia construir livre de interferências emotivas, pois, de certa forma, nessa língua conseguia trabalhar diretamente da inteligência: no idioma de sua intelectualidade dificilmente conseguiu transmitir suas verdadeiras emoções (1).

O primeiro heterônimo, o inglês e juvenil Alexander Search, escreveu cerca de uma centena de poemas (2), na "busca" (Search), ao

(1. - Na sua biografia de Fernando Pessoa, João Gaspar Simões declara que "Se 'pensava' já em inglês, como, de resto, pensará toda a vida, a verdade é que não 'sentia' como inglês, o que, aliás, nunca, em verdade, psicologicamente, virá a acontecer, como veremos" (Vida e Obra de Fernando Pessoa, 2 a edição, Lisboa, Livraria Bertrand, s/d, p. 71) .

(2). - Georg Rudolf Lind afirma que "na famosa arca de Pessoa", havia "as listas completas (ou quase completas) dos Sres. Search e Ch. R. Anon, num total de 115 poesias, escritas todas elas entre 1903 e 1909". G.R. Lind, "A Poesia Juvenil de Fernando Pessoa", Humboldt 8, no 17, 1968, p. 26. 
que parece, de conscientizar seus temas centrais e a melhor maneira de exprimi-los. ,

Nas composições seguintes, ou seja, nos 35 Sonnets e na coletânea The Mad Fiddler, Pessoa deixa entrever que já havia encontrado uma "técnica" de composição poética bem próxima dos ideais propostos nos artigos de $A$ Águia. Em linhas gerais, o último desses artigos, "A Nova Poesia Portuguesa no seu Aspecto Psicológico", considera que a poesia moderna em Portugal seria uma poesia de "vida interior", de "alma" e, portanto, "subjectiva" e, ao mesmo tempo, preocupar-se-ia com a natureza, sendo "por isso também uma poesia objetiva" Assim, caracterizar-se-ia pelo "vago", pela "subtileza" e pela "complexidade" (explicados no mencionado artigo) e, ao mesmo tempo, pela "nitidez", pela "plasticidade" e pela "imaginação" Ao tratar desses elementos responsáveis pela objetividade, Pessoa afirma que tinha en mente a obra dos românticos que "pensam por imagens", imagens provenientes da natureza sentida como real exterior. Em Páginas de Estética e de Teoria e Crítica Literárias, volta ao assunto:

De novo, o que o romantismo trouxe foi o sentimento, propriamente tal, da Natureza. (A renovação da metáfora e da imagem).

Com efeito, se observarmos os poemas ingleses de Pessoa, veremos que, tal como os românticos e simbolistas, tratam de emoções e sensações; a utilização de metáforas "nítidas" e "concretas", à maneira romântica, evita, porém, que o Poeta se perca no "desequilíbrio" "degenerativo" que desprezava nos simbolistas. E as imagens empregadas por Pessoa lembram muito às dos poetas românticos ingleses: Coleridge, Wordsworth, Shelley, Byron, etc. A identidade nessa porção da obra pessoana faz-se mais evidente, pois tendo sido escritos no mesmo idioma, os significantes coincidem: abyss, meadows, glades, sky, etc. Convém acrescentar que esse tipo de metáfora, extraída da natureza concreta, deve ter sido absorvida por compartilharem, Pessoa c esses poetas ingleses, algumas posturas básicas perante o mundo: o platonismo ou transcendentalismo (em Pessoa, com laivos de ocultismo) e a simpatia, o amor, pela Natureza. Dessa forma, não veio apenas a imagem, mas a imagem aglutinada a algumas conotações que possuíam nas obras daqueles poetas.

A fim de observar o que ocorre na poesia inglesa de Pessoa no que diz respeito às metáforas e suas estruturações, focalizaremos ape-

(3). - Páginas de Estética e de Teoria e Crítica Literárias, Textos estabelecidos e prefaciados por Georg Rudolf Lind e Jacinto do Prado Coelho, Lisboa, Ātica, s/d, p. 146. 
nas um conjunto metafórico: aquele relacionado com o claro e o escuro e as cores vivas, como o azul, o verde, o amarelo e o vermelho.

Dentre as metáforas recorrentes nos Poemas Ingleses, cabe a "noite" (night) com seus correlatos "escuro" (dark), "escuridão" (darkness) e a "dia" (day), "luz" (light), "claridąde", "iluminado" (lit), ou ainda a "estrelas que brilham na noite", um dos maiores índices de freqüência. O sentido vem explicado nos Textos Filosóficos:

Simile of "substance and shadow" The realities (secondary) are will (substance) and idea (light), (but a light from within, created by the substance) the shadow they produce is the body. (4)

e ainda,

It is evident then that ideas are real and things shadows incarnate. (5)

Nessa concepção platônica, tudo que se relaciona com luz indicaria o ideal, a essência das coisas; atingir essa luz, penetrar a "sombra", a aparência das coisas em busca de sua essência, eis a meta primordial dos mecanismos conscientes de Pessoa. Opondo-se a essa luz, ao "dia", acha-se a "noite" que indica, portanto, aquela porção de nossa existência indevassável à luz da razão. A "escuridão", como verificaremos a seguir, jamais se apresenta totalmente negra: rasgamna raios ou pontos luminosos, reflexos do mundo exterior, das emoções e sensações, que atingem o pensamento, ou seja, idéias relativas ao mundo sensível. O desespero do poeta de "Ceifeira" vem da impossibilidade de conhecer racionalmente o mundo exterior, pois tudo que lhe chega ao consciente não passa de imagens referidas a esse mundo, infalivelmente deturpadas no decorrer do processo intelectualizador

Para completar esse conjunto metafórico, o Poeta valeu-se dos ulhos, da visão, pois tal sentido é o que mais se presta a interiorizar a "luz" Ainda, ter visão significa também ter conhecimento.

O soneto XIV, dos 35 , demonstra o dilema do precário conhecimento que logramos do mundo exterior, através do conjunto "noite escura" e "estrelas brilhantes":

(4). - Fe`nando Pessoa, Textos Filosóficos, estabelecidos e prefaciados por Antonio de Pina Coelho, vol. I, Lisboa, ed. Ática, 1968, p. 131.

(5). - ibidem, p. 87 
We are born at sunset and we die ere morn,

And the whole darkness of the world we know,

How can we guess its truth, to darkness born,

The obscure consequence of absent glow?

Only the stars to teach us light. We grasp

Their scattered smallnesses with thoughts that stray,

And, though their eyes look through night's complete mask,

Yet they speak not the features of the day.

Why should these small denials of the whole

More than the black whole the pleased eyes attract?

Em síntese: vivemos na escuridão, tendo uma vaga idéia da existência da luz que jaz por trás da aparência das coisas. A "noite", inacessível ao pensamento, encobre essa verdade. As estrelas, "símbolos" dessa realidade, "olhos" de outros seres, distam pequenas e escassas na vasta escuridão por onde vagueia o pensamento.

A esse propósito ocorre lembrar a observação de A. Severino:

A imagem do dia como símbolo paradoxal do que é oculto e misterioso é encontiada a passo e passo na obra poética de Fernando Pessoa, tanto na escrita no vernáculo, como na elaborada em língua inglesa. (6)

No soneto, esses pequenos pontos luminosos atraem a visão mais que a escuridão dominante: tão ínfimos sinais de haver uma Realidade transcendente mantêm o Poeta constantemente na busca de como alcançá-la, motivando-lhe a contínua análise dos processos emotivos e do pensamento. As sensações que temos do mundo exterior fazem que a escuridão nunca se torne absoluta. Caso contrário, parece sugerir o Poeta, não haveria consciência de vida. (7)

Antes de prosseguirmos, cabe lembrar que a reincidência de céus estrelados na poesia romântica tornou a imagem um verdadeiro clichê. Apenas para citar um exemplo, Walt Whitman, que tão profundamente influenciou Pessoa, ao defrontar-se com o céu estrelado, indaga-se acerca da força subjacente ao Universo, como transcendentalista que era. Eis um trecho de "On the Beach at Night Alone":

(6) - A. Severino, "O Ensaio Acerca de Macaulay", in Alfa, Marília, $\mathrm{n}^{\circ} 15$, p. 113. V também a citação da p. 112.

(7) - A propósito de "Dois Excertos de Odes" de Álva־o de Campos, comenta A. Severino: "Fernando Pessoa, ao enfatizar as estrelas, estabelece logo de início o negrume e a luz como qualidades paradoxais inerentes à própria noite" ("A Presença de Milton numa Ode de Álvaro de Campos", Colóquio, Revista de Artes e Letras, ${ }^{\circ} 58$, abril de 1970, p. 58. 
As I watch the bright stars shining, I think a thought of the clef of the universes and of the future.

A vast similitude interlocks all

Contudo, enquanto Whitman apenas detecta o esquema platônico, Pessoa desmonta-lhe os detalhes: o que se vê, o que se busca e quanto pode ser apreendido ou desvendado pelo consciente.

Por volta de 1903, portanto aos 14 anos, Pessoa já pensava dessa forma; comprova-nos um poema encontrado em um caderno de exercícios escolares (8):

The blackest clouds are never packed so tight

That we see not some blue,

The sky is ne'er so dark some ray of light

May not break through.

Nought is more cold than ashes are,

Yet there a fire hath been:

The night around a lonely star

More dark than all is seen.

A ênfase final, porém, é posta na escuridão da noite; por sabermos que há luz, acentua-se o negrume à sua volta; sabermos que há uma realidade que não podemos atingir faz que mais e mais a queiramos e mais nos faça sofrer.

Em 1903 e em 1913, ou alguns anos antes (data em que os sonetos devem ter sido escritos), e mesmo mais tarde, nos heterônimos em vernáculo, as imagens permanecem as mesmas; no referido soneto XIV, porém, o conjunto metafórico vem explicitado. De todas as composições onde aparece, é aí que se encontra da forma mais intelectualizada: ao analisar a imagem, Pessoa disseca a emoção neia vazada, tal qual preconizava em $A$ Nova Poesia Portuguesa. Aliás, esses ensaios só poderiam ter sido escritos por alguém que a essa altura já se houvesse exercitado muito em composições poéticas, visando a uma forma de expressão que condissesse com seus ideais cstéticos - grande parte da poesia inglesa de Pessoa consiste desses exercícios.

Há, contudo, outras conotações de night e day. Alexander Search, em um de seus poemas, usa da analogia convencional razão - dia, como opostos a noite-loucura:

(8) - Hubert Dudley Jennings, "Alguns Aspectos da Vida de Fernando Pessoa na Áfíica do Sul", Colóquio, Revista de Artes e Letras n⿳0 52, fev. de 1969, p. 68. 
But oh! to feel with consciousress'clear sight

Reason's day go to twilight in swift growth,

And the twilight of reason, pale and chill,

Darken towards impenetrable night.

Aqui se acham bem evidentes as relações visão-consciência, razãodia, e a noite impenetrável. (9)

$\mathrm{Na}$ impossibilidade de sondar o mundo sensível, das aparências, pelo pensamento, Pessoa acaba por optar por aquela que designa como a terceira maneira de conhecer a realidade: pelas "faculdades de ordem imaginativa", que "criam outra realidade, que nós sabemus fictícia, mas que deleita por não ser aquela que nos é quotidiana, e por ser uma realidade que é nossa, que nos não é imposta" (10) Assim, Pessoa vê-se a toda hora a considerar a imaginação, ou o sonho, como alternativa para os meios cognoscitivos insuficientes. O sonho aproxima-se mais da Realidade do que o conjunto de noções trazidas pelos sentidos ou abstraídos pelo pensamento, pois apreende, ou cria, um mundo visto na sua integridade. Tais concepções traem o poeta, que vive pela imaginação, pois o fenômeno da criação artística depende quase diretamente dessa maneira de ser: o poema nasce a partir de dados do mundos fornecidos pelas "faculdades imaginativas" No dizer do próprio Pessoa, "A literatura, como toda a arte, é uma confissão de que a vida não basta" (11) e sabe-se que assentou quase toda sua obra nessa premissa. Se Álvaro de Campos levou essa temática ao extremo, Alexander Search é o heterônimo que a conscientizou e discutiu mais aberta e objetivamente. ("Epigram"):

"I love my dreams", I said, a winter morn,

To the practical man, and he, in scorn,

Replied: "I am no slave of the Ideal,

But, as all men of sense, I love the Real"

Poor fool, mistaking all that is and seems!

I love the Real when I love my dreams.

ou ainda ("Doubt"):

p. 29 .

(9). - G. R. Lind, "A Poesia Juvenil de Fernando Pessoa", ed. cit.

(10) - Páginas Intimas e de Auto-Interpretação, Textos estabelecidos e prefaciados por Georg Rudolf Lind e Jacinto do Prado Coelho, Lisboa,

ed. Ática, 1966, p. 313.
(11). - Páginas de Estética e de Teoria e Crítica Literárias, ed. cit., p. 286 . 
Tell me, tell me who dreams most -

He who sees the world aright

Or the man in dreaming lost?

What is true? What is th that seems

The lie that's in reality

Or the lie that is in dreams?

Conclui-se, pois, que a Verdade se mantém inacessível; tanto o sonho como a realidade não passam de "lies", mentiras. (12) Tratase, portanto, do Poeta, plenamente cônscio de o ser, que descreve aqui sua atitude perante as coisas. E essa objetivação de seus processos mentais dá-se, uma vez mais, no idioma de sua inteligência, em inglês.

No campo metafórico, o sonho, fruto da imaginação, não pertence à escuridão porque se verifica no consciente; mas também, não sendo a Realidade mesma que se visa a conhecer, não se mostra iluminado diretamente como, por exemplo, o dia: apresenta-se como um reflexo embaçado de luz; tem certa relação com o Ideal, ou melhor, é a única visão dele permitida ao Poeta, embora apenas uma como que imitação, um reflexo desse Ideal concebido em termos de luz.

O soneto XXII mostra, ou melhor, demonstra "logicamente", como Pessoa sempre o faz nos sonetos, que um dia nublado não deixa de ser essencialmente dia, embora o sol esteja oculto atrás das nuvens:

Even as upon a low and cloud-domed day, When clouds are one cloud till the horizon, Our thinking senses deem the sun away And say " "tis sunless" and there is no sun"; And yet the very day they wrong truth by Is of the unseen sun's effluent essence, The very wo:ds do give themselves the lie, The very thought of absence comes from presence;

Como diz o soneto, logo adiante, "He speaks of light that speaks of absent light": ao verificarmos ausência de luz, revelamos a preocupação com a existência, ou não, da própria luz. Assim, nosso pensamento supõe atrás das nuvens a essência do dia que, por estar enco-

(12). - Note-se, no segundo poema citado, a tentativa de reproduzir o ritmo e até o tom leve das "nursery rhymes" inglesas, muito embo a a problemática aí expressa seja já a típica pessoana. No Primeiro Fausto, aparece um ligeiro eco dessa composição: "Oh vulgar, oh feliz! Quem sonha mais,/Eu ou tu? Tu que vives inconsciente,/Ignorando esse horror que é existir" Fernando Pessoa. Obra Poética, Rio de Janeiro, Aguilar, 1965, p. 459. 
berto, suscitou a questão da ausência do sol. Esse soneto, aliás, nada mais é que a expressão poética do "texto filosófico" anteriormente mencionado. "[ ] idea (light), (but a light from within, created by the substance) the shadow they produce is the body" $\mathrm{E}$ mais, constitui a explicitação da metáfora empregada em outras composições: se traduzirmos o termo deem do terceiro verso por imaginar ao invés de supor, crer, teríamos que o nosso pensamento imagina o sol oculto. Concluir-se-ia, dessa forma, que a essência por detrás da aparência das coisas só pode ser atingida pela imaginação. Na obra de Pessoa o sonho, o imaginado, vem sempre representado por nuvens, pelo encoberto, tal qual a descrição do soneto acima. Como esta fuga para a imaginação vem a ser uma constante no autor de Mensagem, fica explicado o lusco-fusco, o nevoento característico de diversos poemas seus. Palavras como mist, misty, dim aparecem freqüentemente nos poemas em língua inglesa; respondem, até certo ponto, pelo vago, nebuloso, típico de boa parte das composições pessoanas. E a idéia de enevoado, embaçado, vem geralmente relacionada com a palavra dream. sonho.

A criação artística, como vimos, está intimamente ligada com os processos imaginativos. Daí, em "The Poem", ao tratar do poema que está por nascer, Pessoa empregar metáforas semelhantes às que se referem à imaginação e ao sonho:

It has no stanza, verse or word.

Ev'n as I dream it, it is not.

'Tis a mere feeling of it, blurred,

And but a happy mist round thought. (13)

O poema ainda não se formou, não tem estrofes, versos ou palavras; nada se definiu por enquanto; há apenas uma vaga sensação de que possa vir a ser criado. A única realidade consiste em sonhá-lo na sua indefinição: " $a$ fecling of it blurred" $\mathrm{O}$ mero imaginá-lo, entretanto, traz "a happy mist round thought" a névoa com se defronta quem pressente uma realidade para além do alcance do racional, $\mathrm{c}$ uma névoa "alegre", pois dissipa momentaneamente a escuridão ao redor do pensamento.

Da mesma forma, "Suspense", em que o poeta acaba por se queixar de cansaço de só sonhar, trata, nas primeiras estrofes, do conteúdo dos sonhos:

(13). - "The Poem", apud "Oito Poemas Ingleses Inéditos de Fernando Pessoa", de G. R. Lind, in Ocidente, Lisboa, $\mathrm{n}^{\mathrm{Q}}$ 362, junho de 1968, Vol. LXXIV, p. 268. 
I dream, and strange dim powers

My shining sleep assist;

A sound as of coming showers

Creeps towards me, loudly hou's

Lie round me like a mist. (14)

A aparência de sono encobre a realidade interior dos sonhos. Defrontamo-nos com uma concepção similar em "A Sensationist Poem": Let your silence tell me of the numberless dreams that are you" Essa idéia de que o sono não passa de aparência parece vir confirmada pelo adjetivo "shining" que, tal qual o "branco" que analisaremos a seguir, sugere, ao que tudo indica, na obra de Pessoa, o brilho das coisas vistas apenas como exterior, ocas, ou evanescentes. Os sonhos, por trás desse exterior inerte, vêm assistidos por "strange dim powers" (poderes estranhos e anuviados). "Dim," embaçado, anuviado, nos remete ao soneto do dia nebuloso, indicando sua relação com o sonho (explícito no primeiro verso citado). Com efeito, essas "forças pouco nítidas" devolvem ao Poeta as horas passadas, esquecidas. Tais momentos já vividos, por ora apenas relembrados, apresentam-se "like a mist" - envoltos em névoa, demonstram não se tratar de vida real, mas de uma realidade somente atingível pela memória e por processos mentais de ordem imaginativa.

O tom melancólico da composição resulta não só da tristeza de viver em sonhos, impossibilitado de se voltar para a vida sensível, mas também do "encoberto", "embaçado" refletido pelos vocábulos "mist", "dim" e pela expressão "A sound as of coming showers", que traz consigo o "cinza", o "nebuloso", dos dias de chuva. "Antinous", que descreve o imperador Adriano a revolver lembranças dos tempos em que seu escravo ainda vivia, e depois, a imaginar a estátua que lhe erigiria, decorre num dia de chuva, tendo por "cor" dominante o mesmo "cinza" (entre o "branco" do ideal e o "preto" indevassável ao pensamento, entre o "dia" e a "noite", ou ainda como o dia encobe-" to), esse enevoado característico, para Pessoa, de quem vive apenas pela imaginação.

Ao lado das mencionadas, surgem, aqui e ali, nos Poemas Ingleses, outras cores, mais vivas. Como seria de esperar, pertencem, o azul, o amarelo, o verde e o vermelho, àquelas áreas mais diretamente expostas à "luz", ou seja, ostentam cor viva os objetos de certa forma relacionados com o Ideal. A esse respeito, Jacinto do Prado Coslho é de parecer que:

(14) . - "Suspense", ibidem, p. 270. 
A sujeição da imagem do mundo a esquemas mentais refie. te-se na pobreza de exp essões cromáticas, não só pouco rumerosıs, como, não raro, com função simbólica. (15)

Do que nos foi possível observar nos poucos poemas ingleses publicados, as cores vêm, com éeito, empregadas de modo simbólico. Ass.m, uma vez estabelecido o equacionamento cor-significado, ou seja, conhecidas as conotações das cores, verifica-se que os sentidos a elas atribuídos são constantes, confirmam-se a cada passo na leitura da obra de Pessoa.

Blue (azul) liga-se geralmente a céu, sugerindo céu claro, desanuviado, isto é, livre de interferências inquietantes porque inexplicáveis. Cronologicamente, a primeira composição que inclui é o poema de 1903: "The b'ackest clouds are never packd so tight/That we see not some blue" Em português, há um poema em que o sentido vem explícito:

Mas entre mim e as brandas glórias

Deste céu limpo e este ar sem mim

Intervêm sonhos e memórias. (16)

Aqui a aproximação "céu limpo" e "este ar sem mim" indica aquilo que se tornara evidente no soneto XXXV - que céu azul (ou limpo) conota uma coloração ou brilho apenas exterior, implica a incxistência de substância "por detrás"; como, aliás, sucede com o azul do céu que inexiste na realidade. No soneto XXXV, lê-se

The outer day void stitue of lit blue

Is altogether outwa $d$, other, glad

At mere being not-I

O azul iluminado equivale a uma estátua oca e consiste só de exterior; forma sem conteúdo. Ainda que o dia visível pressuponha a existência de luz, o poeta se mantém alheio, defrontando apenas o "invólucro", incapaz de desvendar o Mistério. O brilho exterior pode sugerir falta de vitalidade e até certa frieza. O branco, para Pessoa, parece quase identificar-se com o azul nessas conotações. Em "Anti-

(15). - Jacinto do Prado Coelho, Diversidade e Unidade em Fernando Pessoa, Lisboa, ed. Verbo, $3^{a}$ ed., 1969, p. 172, nota de rodapé: refere-se ao ensaio de Maria Luiza Guerra, $A$ A usência de Cor na Poesia de Álvaro de Campos, sep., de Palestra Lisboa, no 32, 1968.

(16) - Fe nando Pessoa, Obra Poética, ed. cit., p. 165. Todas as demais citações indicadas por número entre parênteses se referem a essa edição. 
nous", por exemplo, a estátua que o imperador Adriano sonha erguer em memória de Antinous "will loom white out of the past" (p. 605) Novamente, o branco qualifica uma estátua, forma de pedra, sem vida. O corpo do escravo também é sempre descrito como sendo branco: "Now is Apollo sad because the stealer/Of his white body is for ever cold" (p. 602), ou ainda: "O father of the gods [but] spare/This boy and his white body (. .)" (p. 604). Há duas interpretações possíveis, sobretudo quando lembramos que, sendo bitínio, Antinous talvez nem fosse tão branco de pele: ou Adriano refere-se em ambos os casos ao corpo já inerte de Antinous, que parece ser a mais provável, ou o "branco" indica uma perfeição apenas física, comparável à das estátuas de Apolo. Nesse caso, a ênfase residiria no prazer sensual que Antinous proporcionava a Adriano, sem maiores inquietações "metafísicas" Também em "Antinous", o Poeta descreve a morte no semblante do jovem escravo como "Death's blue paleness" Aqui houve uma combinação de azul com palidez, portanto algo esbranquiçado, ambos a transmitirem, uma vez mais, uma sensação de frieza, de falta de vida. (17)

Vejamos o que ocorre com o amarelo. Dado à representação do Ideal como "dia", "luz", o amarelo nos traz de imediato a conexão amarelo-brilho. Contudo, nem sempre é assim; pode significar apenas reflexo de um sol já visto no passado, como acontece no soneto XXIV: "Our yellow, local day on its wont jars,/For it hath communed with cin absolute day." As mais das vezes, entretanto, a idéia de amarelado surge sob a forma de golden (dourado), confirmando sua relação com "luz", concebida como um bem, uma riqueza. Enquanto o "azul" e o "branco" demonstram apenas a existência exterior, in.substancial, o "dourado" se apresenta como a consubstanciação da luz, sugerindo a idé a de ouro (maciço, e não estátua oca). (18) Talvez os anéis, supostamente dourados, de certos poemas, estejam vinculados a esta noção de "ouro", de vida Ideal. Em "Meantime", deparamo-nos com "her hands played with rings", e na epígrafe de "A Sensationist Poem", com "Her fingers toyed absently with her rings"

(17). Talvez caiba lembrar, de passagem, o comentá io de Maria da Glória Padrão acerca do "azul"; "Azul é sentimento sem objeto como o movimento de um acordar para o nada (Canc. 102), como tudo o que não existe e em que ele queria acreditar (Canc. 196) (A Metáfora em Fernando Pessoa, Porto, Ed. Inova, 1973, p. 118.). Parece faltar a essas conclusões uma referência à o'igem concreta do azul, extraída certamente da natureza, do céu de sanuviado, referência essa que atenuaria o vago da interpretação citada.

(18) . - Analisando "Paúis", G. R. Lind considera a comp'exidade da imagem "alma em oiro" do primeiro verso, e afirma: "A emoção da alma ao contemplar o por do Sol alia-se à ânsia de Ideal; a palavra ouro é utilizada neste seu sentido extremo tanto por Pessoa como por Sá Carneiro" (Teoria Poética de Fernando Pessoa, Porto, ed. Inova, 1970, p. 42. 
Tratar-se-ia de uma deusa, de uma das Parcas, talvez, ou de personificações de um sonho inatingível a brincar com a Vida? Se assim for, depreender-se-ia não passar a Vida de um joguete nas mãos de deusas caprichosas, o que não estaria totalmente em desacordo com as idéias de Pessoa, sobretudo com aquelas expressas através de Ricardo Reis.

Paradoxalmente, o outro ideal de Pessoa vem transmitido pelo "verde", com tudo que o sugere: árvores, folhas, campos, paisagens, jardins, etc. Tais imagens, sempre distantes, sonhadas, conotam, acima de tudo, lugares onde a natureza viceja e inspira paz. Opõem-se a duas outras constantes na obra de Pessoa: de um lado à "noite", ou ainda, ao "enevoado", ao "cinza" do Poeta que vive preso ao pensamento e, de outro, ao deserto monótono, estéril, da vida daquele a quem privaram de uma existência natural e sensível. Em "Suspense", por exemplo, queixa-se o Poeta de estar "sick of dreaming,/Weary of being the same/Over desert spaces of seeming."

Embora nunca nos sejam revelados pormenores dessas paisagens (como cabe a quem anseia por se ver livre da constante dissecação mental de tudo), tais campos ou ilhas nos lembram as descrições de Wordsworth, Coleridge, Poe, Shelley, Byron, etc., confirmando a tiliação da metáfora pessoana às dos românticos, sobretudo daqueles que lera no período de sua formação intelectual. Por outro lado, a comprovação do sentido atribuído ao verde da natureza pode ser encontrada num poema de Caeiro, o heterônimo whitmaniano, de vida simples, o Mestre, como Pessoa o chamou, talvez por invejar-lhe a existência calma: "Metafísica? Que metafísica têm aquelas árvores?' A de serem verdes e copadas e de terem ramos [ ] Mas que melhor metafísica que a delas,/ Que é a de não saber para que vivem/ Nem saber que o não sabem?" (pág. 207). A conotação do verde coincide, pois, com o ideal de "Ceifeira", cuja imagem deve ter advindo de "The Solitary Reaper" de Wordsworth: o ideal de poder ser plenamente emotivo, sensível, à maneira dos românticos. Como já ficou dito, as imagens devem ter sido absorvidas por Pessoa juntamente com suas conotações, por evocarem uma simpatia mais profunda que apenas sua forma.

Esse ideal verdejante, vislumbram-no os sonhos, a imaginação. Eis como aparecem em alguns trechos dos Poemas Ingleses: "Let the drooping of your eyelids veil landscapes that are far away" diz o Poeta em "A Sensationist Poem", onde se evidencia tratar-se "landscapes" de conteúdo de sonhos; em "Ship sailing out to sea", um dos "Oito Inéditos" publicados por Georg Rudolf Lind, lamenta o Poeta:

There are happier glades

Beyond where I know.

But this is to-day and woe. 
Em outra composição dessa mesma série, "God made my shivering nerves. ", lê-se "Gold.misted green island where my bark doth tend" onde, além de verde, a ilha imaginada afigura-se envolvida por uma névoa dourada, de onde se depreende sua relação com o sonho e com o Ideal. (19)

Relacionados com o elemento verde encontramos as flores, o cainto dos pássaros e um riacho, todos tipicamente românticos. As flores que, como as árvores, vicejam, desabrocham, frutificam, o pássaro que canta sua alegria ou sua dor sem estar a analisá-las (tal qual a "Ceifeira"), e o riacho, água em movimento, oposto ao "deserto", e que, por sua vez, também emite um som "sem razão", refletem todos a vida simples, natural, com que sonha o Poeta irremediavelmente preso ao vaivém do pensamento. Em "Epithalamium" essas imagens aparecem conjugadas, comprovando o relacionamento apontado:

Ye by whose secret presence the trees grow

Green, the flowers bud, and the birds sing free. (pág. 613) (20)

Tendo estabelecido o sentido simbólico dessas cores e dos outros elementos a elas relacionados, vale a pena observar como Pessoa as utiliza. O soneto XXVIII joga com o significado do "verde" e do "branco" de maneira surpreendente, evidenciando, da parte de seu criador, extrema habilidade em explorar poeticamente tais metáforas, absorvidas dos poetas românticos de língua inglesa, na análise de sua problemática:

The edge of the green wave whitely doth hiss

Upon the wetted sand. I look, yet dream.

Surely reality cannot be this!

(19). - Os três poemas citados pertencem à série dos "Oito Poemas Ingleses Inéditos de Fernando Pessoa", de G. R. Lind, já mencionada.

A última formulação lembra muito "Alastor", de Shelley. E, pelo que revela uma exclamação lançada em seu diário, aos 25/9/1907, Pessoa, em dado momento, se identificou com Alastor: "Alas! Poor Alastor! Shelley how I understand thee" (J G. Simões, Vida e Obra de Fernando Pessoa, ed. cit., p. 102).

(20) - Em Mensagem, encontram-se todas essas imagens, dadas claramente como relacionadas com o ideal sonhado:

O sonho é ver as formas invisíveis

Da distância imprecisa, e, com sensíveis

Movimentos da esp'rança e da vontade,

Buscar na linha fria do horizonte

A árvore, a praia, a flor, a ave, a fonte -

Os beijos merecidos da Verdade. (p. 78) 
Quando Pessoa avista a onda ao longe, enxerga-a verde - plena de substância, vitalidade, força, movimento. Ao aproximar-se do Poeta, porém, esvai-se brancamente sobre a areia molhada. O "branco", como das outras vezes, conota insubstancialidade: a espuma branca desfaz-se sem que se possa perscrutar a vitalidade que se presumira na onda, sua essência. O "verde" da onda mantém-se inacessível, só existe na distância, tal como as "landscapes" acima mencionadas. Contudo, a umidade da areia prova que por trás daquela aparência evanescente continuava a existir a essência água. Tanto que o soneto segue, afirmando alguns versos adiante que "Only what in this is not this is real", que retoma a postura platônica de seu criador. $\mathrm{Na}$ análise das metáforas, releva notar o uso do branco, com sua conotação bem definida, em forma de advérbio, whitely, modificando a onomatopéia hiss. A sinestesia, tantas vezes encontrada na obra de Pessoa, se encarrega de combinar diversas sensações, cada uma "nítida" em si, resultando a descrição de uma emoção única porém "complexa", como vem estipulado em $A$ Nova Poesia Portuguesa.

Tal como a onda avistada ao longe, as paisagens tipicamente românticas se colocam, como se verificou, sempre distantes do Poeta, porque, uma vez atingidas, deixariam de ser tão perfeitas, de existir integralmente; só assim imaginadas, intactas, constituem o Ideal, gerando continuamente a esperaça de virem a ser apreendidas na sua totalidade. Adolfo Casais Monteiro, comentando essa contínua obsessão de Pessoa, afirma:

Esse mundo das essências, oculto e impenet ável, é o único para ele real — porque não existe. Pessoa não o pode destruir. porque o pôs fora do alcance da sua máquina mental de destruição. (21)

Por outro lado, poderíamos argumentar que Pessoa, que tanto teme o vazio da "emoção pela emoção", desloca o lirismo, ou os cenários que o motivam, para longe, "fingindo-se" irremediavelmente dissociado da emoção, quando, na realidade, o que o atormenta é uma extrema sensibilidade diante das coisas, e tudo que faz é analisar suas emoções, buscando dominá-las através da objetivação.

Quando não longíquas, se incrustam tais imagens, representativas da vida ideal, em frases negativas. E o que acontece em "Desolation" (22), onde o Poeta lamenta a vida triste que lhe é concedida, como carente de todos esses elementos: trata-se, entre outros, do deserto

(21). - Adolfo Casais Monteiro, Estudos Sobre a Poesia de Fernando Pessoa, Rio de Janei ${ }^{\circ}$, Agir, 1958, p. 137.

(22) - "Oito Poemas Ingleses Inéditos" ed. cit., p. 286. 
desprovido do verde e de água, da praia intocada (uma das metáforas de maior reincidência na poesia de Pessoa, cuja conotação se equipara à "ilha verde aonde, em sonhos, o leva o barco"), da flor que não brotou. Essas formulações negativas indicam que o Poeta não estava apenas descrevendo paisagens mas, à maneira dos poetas metafísicos ingleses, jogava com conceitos, simbolizados em imagens quase convencionais. Dessa forma, ao estruturar verdadeiros clichês românticos em construções sofisticadas, com laivos de barroquismo, acabou por dar-lhes novas configurações, inesperadamente modernas. E o resultado que pretendia ao preconizar a intelectualização da emoção, expressa através de metáforas como as dos românticos. Eis alguns trechos de "Desolation":

Here where, among the grim, deserted stones,

No hope of green for desertness atones,

Or water's sound

Make sweet the solitude around,

Out of my destiny no flowe: was made

To grow.

All in me fated was not even to fade

Or e'en a vain and transient glory show

Gardens fair because therein grows

The unfound rose,

Falta comentar a conotação pessoana do "vermelho" Esta cor vem mencionada nos dois poemas narrativos pertencentes ao "círculo do fenômeno amoroso" e unicamente aí. Tal exclusividade não deve ser fruto do acaso ou coincidência, sobretudo em se tratando de Fernando Pessoa. Em "Antinous", aparece na seguintę frase:

Yet oh that (..) thou

Wert the red flower perfuming my life. (pág. 605)

Adriano lamenta ter que imaginar uma estátua para manter viva a memória do seu amor. Melhor seria se Antinous vivesse como uma "flor vermelha perfumando-lhe a vida" O menino, ou o amor que representava, se compara à flor, símbolo, como se verificou, do "vicejar", da vida natural, sensível. Essa existência simples, instintiva, vem, no caso de Adriano, acrescentada da idéia do prazer sensual. A "flor", por si mesma, representaria a vida sensível; a luxúria, o despertar de emoções fortes parece ter exigido, contudo, uma intensificação da metáfora. De onde o vermelho, sangüíneo, ter-se revelado 
símbolo desse extremo abandono aos sentidos, da vida explicitamente sexual.

O perfume dessa flor se vincula, talvez, à emoção que o envolvia, ou desejadamente o envolvesse; a emoção decorrente da vida amorosa, como o perfume que exala da plenitude vital da flor. Vê-se que, neste caso, tal como ocorre com todo o campo metafórico relacionado com o "verde", a emoção se mantém pura e íntegra, resistente ao pensamento.

Em "Epithalamium", onde reaparece o vermelho, ou melhor, onde Pessoa o empregou pela primeira vez (data de 1913, enquanto "Artinous" traz a data de 1915), o significado pessoano desse cromatismo se revela mais claramente:

In a red bacchic surge of thoughts that beat

On the mad temple.

(pág. 617)

O "vermelho" qualifica as idéias báquicas que batem nas têmporas desvairadas; o pensamento, ao invés de, como nas outras composiçães, reinar tiranicamente, subjugando a emoção, encontra-se di)minado por idéias impregnadas de sensualidade, geradas pela imaginação que prevê os acontecimentos da noite de núpcias. "Flush" e "flushed" (págs. 614 e 618 respectivamente) nesse mesmo poema seriam correlatos do "vermelho": portam, não só a idéia da cor, mas também de calor, de excitação.

A conotação confirma-se quando lembramos que o "vermelho" aparece em inglês exclusivamente nesses dois poemas em que Pessoa se refere abertamente à vida sexual, símbolo do ciclo natural vegetativo da natureza, impulso capaz de abater o consciente.

Nesses dois poemas amorosos, sobretudo em "Epithalamium" deixam de ser os olhos, ou a visão, o sentido dominante; o conhecimento mental cede lugar às mãos, que estabelecem um contato mais direto com os objetos, evidenciando a existência de um concreto tangível. Apenas um exemplo de cada poema. Em "Antinous", deparamo-nos com " $O$ hands that once had clasped Hadrian's warn hands" (pág. 601) e em "Epithalamium", ao referir-se à noiva, diz o Poeta: "her hand,/ Touching the body's warmth of life, doth band/Her thoughts with the rude bridegroom's hand to be" (pág. 614) Nos dois trechos citados, note-se a proximidade do adjetivo warm (quente) como que a ressaltar o calor humano vital.

A obra em vernáculo inclui muitas das metáforas aqui analisadas. Tal qual em inglês, reaparecem sempre com o mesmo sentido. 
Mas tudo leva a crer que foi nos poemas ingleses, como vimos, que Pessoa se exercitou primeiramente nas suas novas e típicas formulações com material metafórico extraído dos poetas românticos ingleses. Nessa parte de sua obra o trabalho de "construção" acha-se mais evidente: os 35 Sonnets, por exemplo, resultam claramente de jogos de palavras e de conceitos, de elaborações bastante intelectualizadas com base em imagens da natureza. (23) Ainda que de maneira um pouco mais velada devido às estruturas menos rígidas, ou por não serem deliberadamente shakespeareanas, o mesmo fenômeno percorre todas as composições inglesas. O inglês, ao que tudo indica, facultava a Pessoa a adaptação aos seus temas de meios expressivos que admirara em outros poetas, pois na língua estrangeira conseguia trabalhar vocábulos diretamente a partir da inteligência ou seja, dissociados da emoção. Daí, por vezes, seus versos ingleses carecerem de emotividade, apesar de lidarem exclusivamente com a vida subjetiva: resultam de uma extrema objetivação, de um processo intelectualizante da emoção. Em português continua havendo intelectualização, mas, devido a ser essa a sua língua, aquela em que "lhe era dado, por certo, descobrir as mais íntimas afinidades entre o que sentia e o como exprimia" (24), o sopro emotivo anima as formulações de aparência simples e fluente, frutos, porém, de vários anos de exercícios na busca de uma expressão poética satisfatória para suas emoções.

(23). - Bem o notou o crítico do The Glasgow Herald ao resenhar "Antinous" e os 35 Sonnets, a 19/9/1918: "They (the sonnets) are full of rich images and deep suggestion, and prick one into thought by their very condensations and obscurities. For behind them is a poet's philosophy, not argued out by syllogism, but by figures of the sea and earth and air, and leaving strangely impressed where mere reasoning might only have provoked. Both books are the work of a strong poetical intelligence"

(24). - João Gaspar Simões, op. cit., p. 118. 